\title{
Increase in poliomyelitis cases in Nigeria
}

Published at www.cmaj.ca on Oct. 2, 2008. Revised Oct. 3, 2008.

$\mathrm{P}$ oliomyelitis has been eliminated from 3 of the 6 World Health Organization regions, including the Americas. The recently reported increase in the number of cases in northern Nigeria is a cause of concern given the spread of polio from Nigeria to many previously polio-free countries in Africa and Asia following a similar increase in 2003.

As of Sept. 3, 2008, there were 612 cases of poliomyelitis reported in Nigeria, compared with 175 cases reported by that date in 2007 . The outbreak is associated with low immunization coverage in the affected region ( $>20 \%$ of children remain unvaccinated). Wild poliovirus type 1 has spread from Nigeria to Benin and Niger, and wild poliovirus type 3 to Chad, which highlights the potential for further international spread. ${ }^{1}$ Although emergency immunization days have been conducted, it is anticipated that, with the rainy season beginning in February and the Hajj in December, there will be more cases. In July and August 2008, Nigeria began 2 large-scale rounds of emergency polio immunization in the northern states.

Outside of Nigeria, endemic polio activity continues in several countries, including India, Afghanistan and Pakistan. However, in 2008, cases of poliomyelitis have been reported in countries that had no reported cases in 2007 (Figure 1). These countries include Sudan, Benin, Ethiopia, Burkina Faso and Nepal. A total of 69 cases have been reported in countries

Box 1: Actions for physicians in Canada regarding poliomyelitis

When seeing patients who are planning to travel to polio-endemic countries:

- Encourage up-to-date immunizations

- Encourage a visit to a travel clinic for specific travel-related advice

When seeing a patient with acute flaccid paralysis:

- Consider poliomyelitis in the differential diagnosis for immigrants or returning travellers from disease-endemic areas

- Conduct appropriate stool testing within 14 days after paralysis onset; tests for poliovirus in stool samples can be conducted at local laboratories

- Report immediately the case of acute flaccid paralysis or poliomyelitis to the local public health authority in which polio is not endemic, for a total of 1119 cases reported to date in 2008.

In previous years, there have been imported cases identified in Canada $^{2}$ as well as Australia. ${ }^{3}$ These cases serve as a reminder that polio-free countries can have disease occurrences and that appropriate immunization is a way to protect individuals (Box 1).

\section{Shalini Desai MD \\ Louise Pelletier MD \\ Michael Garner MSc \\ John Spika MD}

Centre for Immunization and Respiratory Infectious

Diseases

Public Health Agency of Canada

Ottawa, Ont.

Competing interests: None declared.

\section{REFERENCES}

1. Global Polio Eradication Initiative. Wild poliovirus weekly update. Available: www.polioeradication.org/casecount.asp (accessed 2008 Sept 3).

2. Poliomyelitis - Are Canadians still at risk? Paediatr Child Health 2007;12:708. Available: www.pulsus.com/journals/toc.jsp?origPg=toc.jsp\&sCurrPg=journal \&jnlKy=5\&isuKy=745\&\&HCtype=Physician $($ accessed 2008 Sept 22).

3. Public health alert over positive case of polio in Australia. Canberra (Australia): Department of Health and Ageing, Australian Government; 2007. Available: www .health.gov.au/internet/main/publishing.nsf/Content/health-mediarel-cmo-130707 (accessed 2008 Sept 3). 